\title{
The Performance of Environmental, Social, and Governance Investment in Thailand
}

\author{
Chayakrit Asvathitanont ${ }^{1} \&$ Nopphon Tangjitprom ${ }^{1}$ \\ ${ }^{1}$ College of Innovation, Thammasat University, Thailand \\ Correspondence: Nopphon Tangjitprom, College of Innovation, Thammasat University, Thailand. Tel: \\ 66-858-156-177.
}

Received: September 17, 2020

Accepted: November 4, $2020 \quad$ Online Published: December 15, 2020

doi:10.5430/ijfr.v11n6p253

URL: https://doi.org/10.5430/ijfr.v11n6p253

\begin{abstract}
The environmental, social, and governance (ESG) investment has evolved from the concept of socially responsible investing (SRI) starting in the period concerned with the civil rights movement and social responsibility. The concept of socially responsible investing has evolved into sustainable investment focusing on the companies that show concerns about environmental, social, and governance (ESG). This study aims to investigate the performance of ESG investment in the Stock Exchange of Thailand based on the list of companies with good performances in environmental, social and governance known as "ESG100 Companies" in Thailand. The performance of ESG investment is not different from the corresponding benchmarks. However, the risk of ESG portfolio is lower both in term of total risk and systematic risk, which results in the abnormal performance measured by Jensen's Alpha. Finally, the list of ESG100 companies does not provide only static information in portfolio selection, but it can also provide information like the persistence in the list or the new inclusion to the list that can help in constructing the investment portfolio and generate abnormal performance.
\end{abstract}

Keywords: Environment, Social, and Governance (ESG), sustainability, investment performance, investment strategies

\section{Introduction}

The severe rapid change in the Environment, Social and Economics have placed the firms into more volatile situations. The short-term profit oriented without properly taken into account the long-term sustainability factor might have integrated too many risk factors into its performance. There are factors that in earlier periods had shown slow or almost no change such as natural disasters and digital transformations that have turned to be of mega impact at an exponential rate. Thus, the investment portfolio and the capital market were at last put into less predictable returns and more predictable higher risk. Hedging for the volatility is one of the solutions for the investors to manage those risks and maintain the return. However, the rapid change in the ecology of investment has impacted the whole market situation. For instance, the value of global disaster has increased 7.9 times when compared to the period of 1960-1969 and 2000-20009 (EMDAT, 2020).

In addition to natural disasters, the global has encountered increasing problems of an aging society and income inequality as social uncertainty factors. Moreover, the inclusion of Stakeholders improving and extending the implementation of Governance also enabled the firms to increase the sustainability of its performance. The firm could pay well-rounded attention from a variety of inputs that enable better planning, therefore, better long-term performance.

The investment with responsibility principle from the United Nations was launched as the suggested guidance for factors to be focused on for investors which also enable sustainable growth. The UN's Principle of Responsible Investment is one initiative for the investors as well as capital markets not only to mitigate the short-term vulnerable returns but also the long-term contributions to business planning for sustainable growth. Nonetheless, the empirical implication of the investments with Environmental, Social and Governance-known as ESG, has not yet sufficiently drawn high levels of attention from investors especially in the South East Asian.

This study aims to investigate the performance of ESG investments in the Stock Exchange of Thailand. The Stock Exchange of Thailand or SET is the second largest stock exchange in South East Asian in terms of market 
capitalization next to Singapore Exchange (World Federation of Exchanges, 2020). Various portfolio performance measurements are used to determine the performance of ESG investment based on the published list of ESG100 Companies. Moreover, this study examines the dynamics from the changes of the ESG list like the persistent appearance in the list and the new appearances in the list.

\section{Literature Review}

The ESG investment has evolved from the concept of socially responsible investing (SRI). The practice of socially responsible investing was initiated in the 1960s during the period of the civil rights movement and social responsibility (Schueth, 2003). One of the first socially responsible investing index was the Domini Social Index (DSI). The Domini Social Index was developed in 1990 and used as a benchmark for investment portfolios that implemented socially responsible investing. During that period, the Domini Social Index implemented a negative screening by excluding companies producing tobacco or alcohol, involvement in gambling business, or earning a specific portion of revenue from selling military weapons. (Statman, 2000). Subsequently, the concept of socially responsible investing has evolved into the sustainable investment. The sustainable investment focuses on the companies that have concerns about environmental, social, and governance (ESG). This sustainable investment tries to integrate social or environmental concerns with financial returns (Jain et al., 2019).

Many empirical studies examined the performance of ESG investments. The performances of ESG investment were mixed because some studies found the superior return of ESG investment whereas some studies showed contradictory evidence. Some argued that the use of negative screening could exclude some companies involved in the production of tobacco, alcohol, or gambling. The exclusion of these sin stocks could reduce the financial performance of investment portfolio as those stocks had higher expected returns than their comparable ones (Hong \& Kacperczyk, 2009).

In contrast, Guerard (1997) found no difference in performance between the socially screened portfolio and the unscreened portfolio. However, the traditional factors like earning forecast and forecast revisions could provide valuable information to improve the performance for both the socially screened portfolio and the unscreened portfolio. Jain et al. (2019) showed that the performance of the conventional indices was not different from the sustainable indices. However, there was a volatility spillover in both directions between the conventional indices and sustainable indices, which implied that flow of information among them.

There was the evidence from a previous study showing that the companies with higher ESG scores could perform better than their peers in terms of equity returns as well as operating performance (Kotsantonis et al., 2016). Verheyden et al. (2016) study found that using ESG screening could improve the performance of portfolio both in terms of higher returns and lower risks measured by volatility and drawdowns.

How ESG information is integrated into the investment decision was investigated by many previous studies. Under the behavioral finance theories, people may make a decision with perfect rationality, but they make a rational decision with the boundary based on the information accessibility and computational capacities under a specific environment (Simon, 1955). This situation is commonly known as bounded rationality (Simon, 1957; Wheeler, 2020). The bound rationality investors would perceive the investment's benefits as the total sum of not only economic benefits but also social and psychological benefits (Guzavicius et al., 2014).

Environmental, social, and governance or ESG information can be considered as the extension of governance information. The governance considerations by investors in their investment decisions is related to their rationality but the environmental or social considerations in investment decisions can be either or both economic concerns and social and environmental concerns (Sultana et al., 2018). Amel-Zahed and Serafeim (2018) conducted the survey data of senior investment professionals, and the result suggested that environmental, social, and governance or ESG information is material to investment performances. However, the material information from ESG data may vary in amount from countries, industries, and company strategies depending upon the situation in each country, industry, and company. Przychodzen et al. (2016) investigated the predisposition of mutual fund managers to incorporate environmental, social, and governance or ESG information into their investment decision making. They found that the propensity to incorporate ESG information higher for mutual fund managers who were concerned more with the level of business risk, as well as their level of risk aversion and concluded that those mutual fund managers incorporate ESG information with the purpose of mitigating risks.

The lower risk characteristics of ESG investment has been documented in may studies. Eccles et al. (2012) found that the portfolio investing in the companies with good environmental and social policies had lower volatility for both value-weighted and equal-weighted. Kumar et al. (2016) demonstrated that companies with environmental, 
social, and governance or ESG-concern showed lower volatility, but they could generate higher returns than their peers. Verheyden et al. (2016) showed that the investment portfolio with ESG screening had lower tail risks and lower chances of severe losses from daily return. Giese et. al. (2019) compared the investment strategy using ESG rating as a signal compared to traditional common factors like a momentum. They found that the intensity of investment using ESG rating was lower than the momentum strategy. However, the effect of risk reduction from the investment strategy using ESG rating could last for three years.

However, the evidence from some studies showed that ESG investment should be used with caution. Goyal and Aggarwal (2014) found that the ESG portfolio outperformed the market but it had higher total risk and systematic risk than the market portfolio. Alessandrini and Jondeau (2020) studied the use of ESG screening in global portfolio and found that ESG screening does not help in improving the performance measured by Sharpe ratio but could result in regional concentration by companies in European countries rather in United States or emerging countries. Moreover, it could result in sectoral concentration by companies in information technology sector rather than financial or energy sectors.

\section{Data and Methodology}

\subsection{Sample Data}

The investment strategy used in this study is a positive screening that the ESG portfolio is constructed by including the companies with good ESG performances. The list of companies with good performances in ESG or Environmental, Social and Governance is from Thaipat Institute. Thaipat Institute is a Public-Interest Organization that was established in 1999. The organization focuses on the promotion of sustatinability and social responsibility through research, training, and consulting to the private sector in Thailand. Moreover, Thaipat has been certified by Global Reporting Initiative or GRI as a GRI Certified Training Partner since 2013 and became GRI Data Partner in 2016. Thaipat developed the ESG rating model and has published the list of top 100 listed companies based on its ESG rating model known as "ESG100 Companies" since 2015. Thaipat has developed the ESG rating is based on CORE Framwork of Global Initiative for Sustainability Ratings including transparency, impartiality, continuous improvement, inclusiveness, assurability, materiality, comprehensiveness, sustainability context, long-term horizon, value chain, balance, and comparability. Moreover, Thaipat has established the screening criteria in developing the list of ESG100 Companies by including the companies with positive financial performance, proper level of free float, and free from accusation by Securities and Exchange Commission.

The list of ESG100 Companies from the year 2015 to 2018 has been employed in this study to measure the post-performance after the list has been published. The list for the year 2019 has been excluded because the stock performance during the year 2020 is abnormally affected by the COVID-19 pandemic.

The performance of investment has been measured year by year after the publication of the list of ESG100 Companies. Usually, the list was published annually in May. The post-performance is measured from the second half of the year and the first half of the following year. For example, the performance of investment in list of ESG100 Companies for the year 2015 is measured from July 2015 to June 2016. The investment performance for each company is measured from total return index obtained from Datastream.

In Thailand, the equites can be listed on the Stock Exchange of Thailand (SET) or the Market for Alternative Investment (MAI). The Market for Alternative Investment (MAI) is intended for relatively small companies to be listed. The regulation for the Market for Alternative Investment (MAI) is more flexible with fewer requirements and lower paid-up capital required. Usually, around 90\% of the Companies in the list of ESG100 Companies published by Thaipat Institute are from the Stock Exchange of Thailand and only 10\% are from the Market for Alternative Investment (MAI). Therefore, only listed companies in the Stock Exchange of Thailand are used to construct "ESG Portfolio" in this study. The portfolio performance is based on equal weight of all companies in the ESG Portfolio.

The benchmark used in this study is Stock Exchange of Thailand Total Return Index or SET TRI obtained from the Stock Exchange of Thailand. The performance based on total return index includes both capital gain and dividend income. Moreover, SET TRI is also used as the representative of market portfolio of equity investment.

\subsection{Performance Measurement}

After obtaining the performance of investment portfolio based in the list of ESG100 Companies, the investment performance is compared to the benchmark. The performance measurement used in this study concerns both return and risk.

The first measurement is Sharpe Ratio (Sharpe, 1966). The Sharpe Ratio measures the performance investment as the 
ratio between the excess return of portfolio over the risk of portfolio gauged by the standard deviation. The formula for Sharpe Ratio is as follows:

$$
S R=\frac{R_{p}-R_{f}}{\sigma_{p}}
$$

where $S R$ is the Sharpe Ratio of the portfolio, $R_{p}$ is the return of the portfolio, $R_{f}$ is the risk-free rate of return which is proxied by the yield on one-year government bond, and $\sigma_{p}$ is the standard deviation of the portfolio's excess return.

The second measurement is $\mathrm{M}^{2}$ or Modigliani risk-adjusted performance (Modigliani \& Modigliani, 1997). This risk-adjusted performance reflects the portfolio's return adjusted with its risk relative to any specific benchmark. In other words, $\mathrm{M}^{2}$ is the return of portfolio if the risk measured by the standard deviation equals to the benchmark. The formula for $\mathrm{M}^{2}$ is as follows:

$$
M^{2}=\left[\left(R_{p}-R_{f}\right) \times \frac{\sigma_{m}}{\sigma_{p}}\right]+R_{f}
$$

Where $M^{2}$ is the Modigliani risk-adjusted performance, $R_{p}$ is the return of the portfolio, $R_{f}$ is the risk-free rate of return which is proxied by the yield on one-year government bond, $\sigma_{p}$ is the standard deviation of the portfolio's excess return, and $\sigma_{m}$ is standard deviation of the market portfolio or benchmark portfolio.

The above two measurements are based on the standard deviation in measuring the risk of the portfolio. For a well-diversified portfolio, only systematic risk should be concerned as in the capital asset pricing model or CAPM (Sharpe, 1964; Lintner; 1965; Mossin; 1966). Therefore, the third measurement is Jensen's Alpha (Jensen, 1968). The Jensen's Alpha is the abnormal performance or abnormal return, which is the difference between the portfolio's return and the expected return estimated from the capital asset pricing model. The formula for Jensen's Alpha is as follows.

$$
\alpha=R_{p}-\left[R_{f}+\beta\left(R_{p}-R_{f}\right)\right]
$$

where $\alpha$ is the Jensen's Alpha or abnormal return of the portfolio, $R_{p}$ is the return of the portfolio, $R_{f}$ is the risk-free rate of return which is proxied by the yield on one-year government bond, and $\beta$ is the beta of the portfolio used for measuring systematic risks. In this study, the beta of portfolio was calcualed as follows.

$$
\beta=\frac{\sigma_{p, m}}{\sigma_{m}^{2}}
$$

Where $\beta$ is the beta of the portfolio, $\sigma_{p, m}$ is the covariance between the portfolio's return and market portfolio's return and $\sigma_{m}^{2}$ is the variance of market portfolio's return.

\section{Analysis and Results}

\subsection{Performance of ESG Investment}

In this study, the ESG portfolio is constructed based on the list of ESG100. As mentioned earlier, the list is usually published in May, the performance of ESG portfolio is measured from the second half of the year and the first half of the following year. The construction of ESG portfolio starts from the beginning of July 2015 based on the list of ESG100 Companies for the year 2015. Thereafter, the ESG portfolio would be rebalanced in the beginning of July 2016 based on the list of ESG100 Companies for the year 2016. This process continues until the end of June 2019 to obtain the overall performance of the ESG portfolio. Table 1 report the description of return and risk year-by-year during the period of study for ESG portfolio and market portfolio used as the benchmark.

Table 1. Return and risk of ESG portfolio

\begin{tabular}{lllll}
\hline Year & $\mathbf{2 0 1 5 - 2 0 1 6}$ & $\mathbf{2 0 1 6 - 2 0 1 7}$ & $\mathbf{2 0 1 7 - 2 0 1 8}$ & $\mathbf{2 0 1 8 - 2 0 1 9}$ \\
\hline ESG Portfolio & & & & \\
\hline Average Return & $0.95 \%$ & $18.05 \%$ & $-0.31 \%$ & $9.88 \%$ \\
\hline Standard Deviation & $12.43 \%$ & $12.89 \%$ & $8.23 \%$ & $10.50 \%$ \\
\hline Beta & 0.775 & 1.026 & 0.724 & 0.883 \\
\hline
\end{tabular}




\begin{tabular}{lllll}
\hline Market Portfolio (Benchmark) & & & & \\
\hline Average Return & $0.47 \%$ & $13.11 \%$ & $5.05 \%$ & $12.60 \%$ \\
\hline Standard Deviation & $15.01 \%$ & $11.17 \%$ & $9.39 \%$ & $11.05 \%$ \\
\hline
\end{tabular}

From Table 1, the number of stocks in ESG portfolio is 88-94 stocks in each year during the study period. The stocks listed in the Stock Exchange of Thailand have been included in this study. Moreover, the stocks that were delisted or merged have been excluded. The returns of ESG portfolio are higher than the benchmark during the first two years but lower during the last two years. The standard deviations of ESG portfolio are lower than the benchmark for three out of four years. The betas of ESG portfolio are also lower than one for three out of four years. This can briefly illustrate the characteristics of lower risk for ESG portfolio. There is only one year, during the year 2016-2017, that the risks of ESG portfolio are relatively high as the standard deviation is higher than the benchmark and the beta is higher than one.

To compare the performance of the ESG portfolio, this study construction the ESG portfolio which is re-balanced based on the new list of ESG100 Companies year-by-year for four-year period starting from July 2015 to June 2019. Table 2 reports the overall performance of the ESG portfolio and benchmark.

Table 2. Overall performance of ESG portfolio

\begin{tabular}{lll}
\hline & ESG Portfolio & Benchmark \\
\hline Average Return & $7.13 \%$ & $7.80 \%$ \\
\hline Standard Deviation & $10.41 \%$ & $11.82 \%$ \\
\hline Sharpe Ratio & 0.538 & 0.530 \\
\hline $\mathrm{M}^{2}$ & $7.89 \%$ & \\
\hline Beta & 0.815 & \\
\hline Jensen's Alpha & $1.04 \%$ & \\
\hline
\end{tabular}

From Table 2, the return of ESG portfolio is 7.13\% per annum, which is slightly lower than the return of benchmark of $7.80 \%$ per annum. However, the standard deviation of ESG portfolio is only $10.41 \%$ compared to the benchmark of $11.82 \%$. To integrate both return and risk to measure the investment performance, this study uses Sharpe Ratio and $\mathrm{M}^{2}$ as the performance indicator. The Sharpe Ratio measures the excess return per one unit of risk measured by the standard deviation. The Sharpe Ratio of ESG portfolio is 0.538, which is slightly higher than the benchmark of 0.530. This means that the ESP portfolio can generate higher excess return per one unit of risk than the benchmark.

The $\mathrm{M}^{2}$ or Modigliani risk-adjusted performance measures the return of portfolio if the risk measured by the standard deviation equals the benchmark. From Table 2, the $\mathrm{M}^{2}$ of ESG portfolio is $7.89 \%$ per annum. This means that if the risk of ESG portfolio is adjusted to be equated with the benchmark, the equivalent return of ESG portfolio would be $7.89 \%$, which is higher than the benchmark return of $7.80 \%$. Therefore, based on the above results, the performance of ESG portfolio in term of risk-return is slightly better than the benchmark.

Moreover, if only systematic risks are considered, the beta of ESG portfolio is only 0.815 , which is lower than the market beta of one. Then, the Jensen's Alpha is estimated for ESG portfolio based on the concept of Capital Asset Pricing Model (CAPM). The ESG portfolio can generate the alpha at $1.04 \%$, which means the ESG portfolio can generate the abnormal return of $1.04 \%$ per annum.

Next, the construction of ESG portfolio is altered by other settings. First, all companies in the list of ESG100 Companies would be included regardless that they are listed in the Stock Exchange of Thailand (SET) or the Market for Alternative Investment (MAI). Therefore, the number of stocks in this ESG portfolio is 98-100 stocks in each year during the study period. Second, the companies used to construct ESG portfolio are filtered by operating performance. The operating performance was reported to have the impact on the equity price like earnings, sales, or other operating performances (Yooyanyong et al., 2020). Then, these companies are ranked by the operating performance using the return on equity. Only 50 companies with highest return on equity are included in this portfolio, which is called ESG portfolio with operating performance. The data about the return on equity was 
obtained from Datastream. Table 3 reports the performance of ESG portfolios in other settings from July 2015 to June 2019.

Table 3. Comparison performance of ESG portfolio stocks

\begin{tabular}{llll}
\hline & ESG Portfolio & $\begin{array}{l}\text { ESG Portfolio including } \\
\text { both SET \& MAI }\end{array}$ & $\begin{array}{l}\text { ESG Portfolio with } \\
\text { Operating Performance }\end{array}$ \\
\hline Average Return & $7.13 \%$ & $6.75 \%$ & $7.20 \%$ \\
\hline Standard Deviation & $10.41 \%$ & $10.48 \%$ & $11.16 \%$ \\
\hline Sharpe Ratio & 0.538 & 0.498 & 0.508 \\
\hline $\mathrm{M}^{2}$ & $7.89 \%$ & $7.42 \%$ & $7.54 \%$ \\
\hline Beta & 0.815 & 0.813 & 0.847 \\
\hline Jensen's Alpha & $1.04 \%$ & $0.98 \%$ & $0.87 \%$ \\
\hline
\end{tabular}

From Table 3, the first column is the performance of the original ESG portfolio as reported in the previous table. This original ESG portfolio includes only companies listed in the Stock Exchange of Thailand. The second column is the performance of ESG portfolio including companies listed in both the Stock Exchange of Thailand and the Market for Alternative Investment.

The return of this new portfolio reduces to $6.75 \%$ per annum with slightly higher standard deviation of $10.48 \%$. This results in poorer performance in term of return and risk. The Sharpe Ratio decreases to 0.498 and the $\mathrm{M}^{2}$ reduces to $7.42 \%$ per annum, which is lower than the market portfolio or benchmark portfolio. Moreover, the Jensen's Alpha is lower with only $0.98 \%$ per annum.

One reason that the return of this new portfolio is poorer compared to the original ESG portfolio is from the inclusion of stocks from the Market for Alternative Investment. During the period of study, the average market return for the Stock Exchange of Thailand was 7.80\% per annum. However, the average return of the Market for Alternative Investment (MAI) was negative in that period.

The third column of Table 3 is the performance of ESG portfolio with operating performance. The return of ESG portfolio with operating performance is slightly higher than the original ESG portfolio at $7.20 \%$ per annum. However, the standard deviation is also higher to $11.16 \%$. This results in a lower Sharpe Ratio to 0.508 . Moreover, the $\mathrm{M}^{2}$ also reduced to $7.54 \%$ per annum. The Jensen's Alpha is also lowered to $0.87 \%$ per annum.

Therefore, the performance of ESG portfolio by including more stocks from the Market for Alternative Investment (MAI) or including less stocks based on operating performance using only 50 stocks with highest return on equity is not better in term of return and risk performance.

\subsection{Dynamic of ESG and Investment Performance}

In this session, the dynamic from the changes of ESG list would be discussed. This list of ESG100 Companies has been published on annual basis. In each year, there are some companies that are newly included in the list and some companies are excluded from the list. The companies that are in the list for many consecutive years could reflect the persistent in their ESG practices and should be included in the ESG investment.

However, due to limitation of the data, the ESG portfolio using the companies that are listed in many consecutive years is also limited. The first available list of ESG100 Companies is for the year 2015. To construct the ESG portfolio including the companies that are persistent in their ESG practices, the ESG portfolio is based on the companies that appear in the list of ESG100 Companies for four consecutive years during the year 2015-2018. There are 37 stocks included in this ESG portfolio. The performance of this ESG portfolio is measured from July 2018 to June 2019. Table 4 reports the performance of ESG portfolio for stocks in the ESG list for four consecutive years. 
Table 4. Performance of ESG portfolio for stocks in the ESG list for four consecutive years

\begin{tabular}{lll}
\hline & ESG Portfolio & Benchmark \\
\hline Average Return & $14.01 \%$ & $12.60 \%$ \\
\hline Standard Deviation & $10.14 \%$ & $11.05 \%$ \\
\hline Sharpe Ratio & 1.211 & 0.983 \\
\hline $\mathrm{M}^{2}$ & $15.12 \%$ & \\
\hline Beta & 0.825 & \\
\hline Jensen's Alpha & $3.31 \%$ & \\
\hline
\end{tabular}

From Table 4, the return of ESG portfolio is $14.01 \%$ per annum, which is higher than the return of benchmark of $12.60 \%$ per annum. The standard deviation of ESG portfolio is $10.14 \%$, which is lower than the benchmark of $11.05 \%$. With higher return and lower risk, the Sharpe Ratio of ESG portfolio is 1.211, which is much higher than the benchmark of 0.983 . The $\mathrm{M}^{2}$ shows that if the risk of ESG portfolio is adjusted to be equated with the benchmark, the equivalent return of ESG portfolio would be $15.12 \%$, which is much higher than the benchmark return of $12.60 \%$. Moreover, the ESG portfolio can generate the alpha or abnormal return of at $3.31 \%$ per annum, which is considerable.

Therefore, this result shows that investing in companies that are in the ESG list for many consecutive years can improve the investment performance. The companies that are in the ESG list for many consecutive years are the companies with persistence in their ESG practices. However, this result should be considered with caution. Due to limitations in term of availability of ESG list, the performance of ESG portfolio for stocks in the ESG list for four consecutive years can be measured for only a one-year period. In the future, this proposition should be further examined in order to draw conclusions about the performance of ESG investment with persistence in ESG practices.

Another aspect of the dynamic from the changes of ESG list is about the new companies that are included in the ESG list. As this list of ESG100 Companies has been published on an annual basis, there are some companies that are newly included in the list every year. Therefore, the new ESG portfolio can be constructed using the companies that are newly included in the ESG list in each year. There are 17-45 stocks included in this ESG portfolio. Table 5 reports the performance of ESG portfolio for new stocks including in the ESG list starting from July 2016 to June 2019.

Table 5. Performance of ESG portfolio for new stocks including in the ESG list

\begin{tabular}{lll}
\hline & ESG Portfolio & Benchmark \\
\hline Average Return & $14.69 \%$ & $10.25 \%$ \\
\hline Standard Deviation & $10.94 \%$ & $10.55 \%$ \\
\hline Sharpe Ratio & 1.201 & 0.824 \\
\hline $\mathrm{M}^{2}$ & $14.23 \%$ & \\
\hline Beta & 0.859 & \\
\hline Jensen's Alpha & $5.67 \%$ & \\
\hline
\end{tabular}

From Table 5, the return of ESG portfolio is $14.69 \%$ per annum, which is much higher than the return of benchmark of $10.25 \%$ per annum. The standard deviation of ESG portfolio is $10.94 \%$, which is slightly higher than the benchmark of $10.55 \%$. The Sharpe Ratio of ESG portfolio is 1.201, which is much higher than the benchmark of 0.824. The $\mathrm{M}^{2}$ shows that if the risk of ESG portfolio is adjusted to be equated with the benchmark, the equivalent return of ESG portfolio would be slightly lower to $14.23 \%$ but it is still much higher than the benchmark return of $10.25 \%$. Moreover, the ESG portfolio can generate the alpha or abnormal return of at $5.67 \%$ per annum, which is considerable.

This result shows that investing in the companies that are newly included in the ESG list year-by-year can generate considerable return with slightly higher risk. In term of return and risk performance, this ESG portfolio can substantially outperform the market benchmark. Therefore, the ESG list contains quite useful information for 
investments. Besides the static list of ESG Companies that can be used to construct the investment portfolio, dynamics from the changes of ESG list can also provide useful information for investment strategies like the persistence and the inclusion of new companies in the ESG list.

\section{Conclusion}

This study aims to investigate the performance of ESG investment in the Stock Exchange of Thailand. The investment strategy used in this study is a positive screening that the ESG portfolio is constructed by including the companies with good ESG performance based on the list of companies with good performance in ESG or Environmental, Social and Governance known as "ESG100 Companies" in Thailand.

The ESG portfolio shows a slightly lower return and risk than the benchmark. The return-risk performance measured by $\mathrm{M}^{2}$ shows it to be quite comparable to the benchmark. This evidence is against the evidence of underperformance of ESG investment Hong and Kacperczyk (2009). However, the performance of ESG investment does not clearly overperform the benchmark with higher returns and lower risks as documented in previous studies (Kotsantonis et. al., 2016; Verheyden et. al., 2016).

The interesting point in the performance of ESG portfolio is from the risk perspective. The risk of ESG portfolio is lower both in term of total risk and systematic risk. Especially for systematic risk, the beta of ESG portfolio is clearly below one, which results in the abnormal performance measured by Jensen's Alpha. This evidence supports many previous studies showing that ESG investment could help in reducing the risk of investment portfolio (Eccles et. al., 2012; Kumar et. al., 2016; Verheyden et. al., 2016)

This study also examines the dynamic of ESG portfolio by examining the persistent appearance in the list and the new appearance in the list. For the persistence of ESG performance, the ESG portfolio is constructed by including only companies in the ESG list for the consecutive four years. This ESG portfolio can clearly outperform the benchmark with the abnormal return measured by Jensen's Alpha of $3.31 \%$ per year. However, this result should be considered with caution due to the availability of ESG list. In the future, this proposition should be further examined in order to draw conclusions about the performance of ESG investment with persistence in ESG practices. For the new appearance in the ESG list, the ESG portfolio can be constructed using the companies that are newly included in the ESG list in each year. The performance of this ESG portfolio can also outperform the benchmark with the abnormal return measured by Jensen's Alpha of $5.67 \%$ per year.

Based on the portfolio theory, the investment portfolio using ESG screening can reduce the level of diversification that can result in underperformance. In this study, the ESG portfolio with lower diversification can achieve lower level of systematic risk with comparable returns. One reason to explain this result is the use of ESG screening can help in excluding relatively high-risk stocks. Moreover, the list of ESG100 companies does not only provide static information in portfolio selection, but it can also provide information like the persistence in the list or the new inclusion to the list that can help in constructing the investment portfolio and generate abnormal performance.

\section{References}

Amel-Zahed, A., \& Serafeim, G. (2018). Why and how investors use ESG information: evidence from a global survey. Financial Analyst Journal, 74(3), 87-103. https://doi.org/10.2469/faj.v74.n3.2

Eccles, R., Ioannou, I., \& Serafeim, G. (2012). The impact of corporate sustainability on organizational processes and performance. Management Science, 60(11), 2835-2857. https://doi.org/10.1287/mnsc.2014.1984

EMDAT. (2020). OFDA/CRED International disaster database. Retrieved from https://www.emdat.be/

Fabio, A., \& Jondeau, E. (2020). Optimal strategies for ESG portfolios. Swiss Finance Institute Research Paper No. 20-21. Retrieved from https://ssrn.com/abstract $=3578830$

Giese, G., Lee, L. E., Melas, D., Nagy, Z., \& Nishikawa, L. (2019). Foundations of ESG investing: how ESG affects equity valuation, risk, and performance. Journal of Portfolio Management, 45(5), 69-83. https://doi.org/10.3905/jpm.2019.45.5.069

Goyal, M. M., \& Aggarwal, K. (2014). ESG index is good for socially responsible investor in India. Asian Journal of $\begin{array}{llll}\text { Multidisciplinary } & \text { Studies, } & \text { 2(11). } & \text { Retrieved }\end{array}$ http://www.ajms.co.in/sites/ajms2015/index.php/ajms/article/view/727

Guerard, J. B. (1997). Additional evidence on the cost of being socially responsible in investing. Journal of Investing, 6(4), 31-36. https://doi.org/10.3905/joi.1997.408433

Guzavicius, A., Vilkè, R., \& Barkauskas, V. (2014). Behavioural finance: corporate social responsibility approach. 
Procedia - Social and Behavioral Sciences, 156, 518-523. https://doi.org/10.1016/j.sbspro.2014.11.232

Hong, H., \& Kacperczyk, M. (2009). The price of sin: the effects of social norms on markets. Journal of Financial Economics, 93(1), 15-36. https://doi.org/10.1016/j.jfineco.2008.09.001

Jain, M., Sharma, G. D., \& Srivastava, M. (2019). Can sustainable investment Yield Better financial returns: a comparative study of ESG indices and MSCI indices. Risks, 7(1), 15. https://doi.org/10.3390/risks7010015

Jensen, M. C. (1968). The performance of mutual funds in the period 1945-1964. Journal of Finance, 23(2), 389-416. https://doi.org/10.1111/j.1540-6261.1968.tb00815.x

Kotsantonis, S., Pinney, C., \& Serafeim, G. (2016). ESG integration in investment management: myths and realities. Journal of Applied Corporate Finance, 28(2), 10-16. https://doi.org/10.1111/jacf.12169

Kumar, N. A., Smith, C., Badis, L., Wang, N., Ambrosy, P., \& Taveres, R. (2016). ESG factors and risk-adjusted performance: a new quantitative model. Journal of Sustainable Finance \& Investment, 6(4), 292-300. https://doi.org/10.1080/20430795.2016.1234909

Lintner, J. (1965). Security prices, risk and maximal gains from diversification. Journal of Finance, 20, 587-615. https://doi.org/10.1111/j.1540-6261.1965.tb02930.x

Modigliani, F., \& Modigliani, L. (1997). Risk-adjusted performance. Journal of Portfolio Management, 23(2), 45-54. https://doi.org/10.3905/jpm.23.2.45

Mossin, J. (1966). Equilibrium in a capital asset market. Econometrica, 35, 768-83. https://doi.org/10.2307/1910098

Przychodzen, J., Gómez-Bezares, F., Przychodzen, W., \& Larreina, M. (2016). ESG Issues among fund managers - factors and motives. Sustainability, 8(10), 1078. https://doi.org/10.3390/su8101078

Schueth, S. (2003). Socially responsible investing in the United States. Journal of Business Ethics, 43, 189-194.

Sharpe, W. F. (1964). Capital asset prices: a theory of market equilibrium under conditions of risk. Journal of Finance, 19, 425-42. https://doi.org/10.2307/2977928

Sharpe, W. F. (1966). Mutual fund performance. Journal of Business, 39(1), 119-138. Retrieved from https://www.jstor.org/stable/25074988

Simon, H. A. (1955). A behavioral model of rational choice. The Quarterly Journal of Economics, 69(1), 99-118. https://doi.org/10.2307/1884852

Simon, H. A. (1957). Model of Man: Social and rational, mathematical essays on rational human behavior in society setting. Wiley, New York.

Statman, M. (2000). Socially responsible mutual funds. Financial Analyst Journal, 56(3), 30-39. https://doi.org/10.2469/faj.v6.n3.2358

Sultana, S., Zainal, D., \& Zulkifli, N. (2018). Environmental, Social and Governance (ESG) and investment decision in bangladesh. Sustainability, 10(6), 1831. https://doi.org/10.3390/su10061831

Verheyden, T., Eccles, R. G., \& Feiner, A. (2016). ESG for all? The impact of ESG screening on return, risk, and diversification. Journal of Applied Corporate Finance, 28(2), 47-55. https://doi.org/10.1111/jacf.12174

Wheeler, G., \& Bound Rationality. (2020). The Stanford Encyclopedia of Philosophy, Fall 2020 Edition. In E. N. Zalta (Ed.), forthcoming.

World Federation of Exchanges. (2020). 2019 Annual Statistics Guide. Retrieved from https://www.world-exchanges.org/our-work/articles/2019-annual-statistics-guide

Yooyanyong, P., Suwanragsa, I., \& Tangjitprom, N. (2020). The accuracy of various value drivers of price multiple method in determining equity price. Journal of Asian Finance, Economics and Business, 7(1), 29-36. https://doi.org/10.13106/jafeb.2020.vol7.no1.29

\section{Copyrights}

Copyright for this article is retained by the author(s), with first publication rights granted to the journal.

This is an open-access article distributed under the terms and conditions of the Creative Commons Attribution license (http://creativecommons.org/licenses/by/4.0/). 